Check for updates

Cite this: RSC Adv., 2018, 8, 1116

Received 19th October 2017

Accepted 15th December 2017

DOI: 10.1039/c7ra11534b rsc.li/rsc-advances

\section{Chemical reaction-transport model of oxidized diethylzinc based on quantum mechanics and computational fluid dynamics approaches $\uparrow$}

\author{
Jian Li, ${ }^{a}$ Hanlin Gan, (D) ${ }^{\mathrm{b}}$ Yifeng $\mathrm{Xu}{ }^{\mathrm{a}}$ Chaoyang Wang, ${ }^{\mathrm{b}}$ Feng Long Gu (D)*b \\ and Gang Wang (iD *ac
}

\begin{abstract}
We developed and studied a chemical reaction-transport model for the production of zinc oxide $(\mathrm{ZnO})$ with diethylzinc (DEZn) and oxygen $\left(\mathrm{O}_{2}\right)$. It was confirmed that a large number of $\mathrm{ZnO}$ particles were generated during the growth process by testing the internal particles of the cavity by $X$-ray diffraction. The formation of $\mathrm{Zn}_{3} \mathrm{O}_{3}$ in the gas phase reaction was simulated using density functional theory, and the effect of nucleation and formation of nanoparticles on the growth of the films was revealed. We also speculate that the adsorption of $\mathrm{Zn}$-containing gas on the wall is the main route by which a $\mathrm{ZnO}$ film is formed. The mechanism calculated by quantum chemistry was applied in computational fluid dynamics (CFD) simulations using Fluent14.0 software, and the concentration distribution and gas reaction path of the reaction chamber were calculated and analyzed. Finally, a 9 gas phase reaction model and an 8 surface reaction model were established. Together with the transport model, a complete chemical reactiontransport reaction model was constructed for the ZnO-MOCVD cavity. The validity of the model was verified, and the optimum temperature range of DEZn and oxygen-stabilized growth of $\mathrm{ZnO}$ films was determined to be $673-873 \mathrm{~K}$. Using the results of the chemical reaction transport model, the geometry and operation parameters of the reactor can be optimized to improve the characteristics of the epitaxial layer.
\end{abstract}

\section{Introduction}

$\mathrm{ZnO}$ has attracted increasing attention in recent years as a new type of wide bandgap semiconductor material. ${ }^{1-3} \mathrm{ZnO}$ has good physical properties: a direct bandgap band structure, room temperature bandgap of $3.37 \mathrm{eV}$, and exciton binding energy of $60 \mathrm{meV},{ }^{4}$ which are the necessary conditions for high-efficiency ultraviolet light emission at room temperature. The use of light emitting diodes as blue-violet (LED) and UV laser (LD) has broad prospects for development for application as UV detectors, thin film transistors, spin field-effect transistors, and nanodevices. ${ }^{5,6} \mathrm{ZnO}$ films can be prepared via many methods, including sputtering, pulsed-laser deposition (PLD), molecular beam epitaxy (MBE), sol-gel method, spray pyrolysis, and metal organic chemical vapor deposition (MOCVD). MOCVD is an important chemical process in the semiconductor industry that

${ }^{a}$ School of Electronics and Information Technology, Sun Yat-sen University, Guangzhou 51000, China. E-mail: stswangg@mail.sysu.edu.cn

${ }^{b}$ Key Laboratory of Theoretical Chemistry of Environment, Ministry of Education, School of Chemistry and Environment, South China Normal University, Guangzhou 510006, China. E-mail: gu@scnu.edu.cn

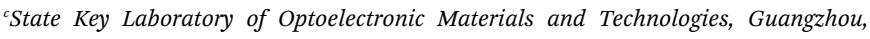
510275, China

$\dagger$ Electronic supplementary information (ESI) available. See DOI: $10.1039 / \mathrm{c} 7 \mathrm{ra} 11534 \mathrm{~b}$ is used to produce thin film materials and high-tech devices because of this method's delivery of high quality films with a uniform and controllable growth source and rapid, large-area, and simultaneous growth. However, there are many complicated physical and chemical processes at work in MOCVD, and the reaction mechanism and growth kinetics are very complex. ${ }^{7-11}$ Mastering this technology to grow high-quality ZnO films requires a full understanding of the chemical reaction path that occurs during $\mathrm{ZnO}$ growth. The optimization of the reactor design is of great significance to the production of highquality films.

Given the variety of substrate surfaces and the uncertain electronic structure of the solid surface, it is more challenging to obtain the parameters of the surface reaction rate than those of the gas phase reaction rate. At present, most of the chemical kinetic parameters of surface reactions are only numerical estimates. The mechanism of III-V compound, ${ }^{\mathbf{1 2}-21}$ such as GaAs, InP, InGaAsP, GaN, and AlN, mainly focus on gas phase reactions. Theodoropoulos et al. ${ }^{17}$ expressed the kinetic parameters in terms of total bimolecular collision rates to represent the pre-exponential factors of the adsorption reaction when they studied the deposition of GaN thin films in MOCVD. Only a few of the kinetic parameters including the activation energy and the pre exponential factor used for gas phase reactions are experimentally obtained test values, and the rest are 
calculated or estimated by quantum chemical methods. In the case of InP growth, Theodoropoulos et al. ${ }^{21}$ took the wall reaction rate parameters (activation energy and pre-exponential factor) as adjustable parameters. These parameters were determined by fitting the experimental values of InP growth rate.

However, relatively few studies have been done on the compounds of the group II-VI. ${ }^{22-27}$ Dumont et al. used metalorganic chemical vapor deposition to oxidize DEZn and deposited a polycrystalline transparent semiconducting $\mathrm{ZnO}$ film. ${ }^{22}$ They found that the deposition process of thin films can be a complex multi-step oxidation process, consisting of a series of free radical reactions. Stanley and Schlegel studied the reaction process of DEZn and $\mathrm{H}_{2} \mathrm{O}$ and pointed out some of the probable intermediates and pathways for gas phase reactions involved in zinc oxide chemical vapor deposition. ${ }^{23}$ However, this study only considered the thermodynamics, and no chemical reaction mechanism gave a full path. Maejima et al. installed a Fourier transform infrared spectrometer (FTIR) on a ZnO MOCVD system. ${ }^{27}$ They used the DEZn and $\mathrm{N}_{2} \mathrm{O}$ reactions to grow the chemical gas phase reactions in the $\mathrm{ZnO}$ process and inferred the simple gas phase pre-reaction process between DEZn and $\mathrm{N}_{2} \mathrm{O}$. So far, the kinetic parameters of the chemical mechanisms of the compounds of II-VI group are few and far between, which limits the understanding of the MOCVD reaction cavity flow and the growth of the films. Development of an understanding of chemistry and reaction mechanisms underlying MOCVD of $\mathrm{ZnO}$ is critical, therefore, to the fabrication of oxide-based devices.

In this study, a vertical rotating ZnO MOCVD reaction chamber was used as a prototype, and quantum chemical calculations were used to investigate the DEZn and $\mathrm{O}_{2}$ reaction to develop a chemical reaction pathway. The kinetics of the reaction system of gaseous $\mathrm{ZnO}$ and the chemical reaction path as well as the kinetic parameters were calculated by computational fluid dynamics (CFD) simulation as input parameters for constructing a chemical reaction-transport model for DEZn oxidation. The deposition rate behavior of $\mathrm{ZnO}$ with temperature is in agreement with that reported in literature. Moreover, further studies were conducted on the MOCVD reaction chamber components and chemical reactions, and the growth process of $\mathrm{ZnO}$ in the $\mathrm{ZnO}-\mathrm{MOCVD}$ reaction cavity was determined. The proposed model may become a useful tool for reactor design, optimization, and scale-up of ZnO MOCVD.

\section{Reaction paths and kinetic parameters}

In the process of growing $\mathrm{ZnO}$ in MOCVD using DEZn and $\mathrm{O}_{2}$, adjusted according to different process parameters, the general set of chamber pressure range is 6-20 tor, the substrate temperature is $723-823 \mathrm{~K}$, the total flow control between $15-30$ slm, the growth time of 45-70 $\mathrm{min}$, nano deposition thickness is about 200-300 $\mathrm{nm}$. During maintenance of the ZnO-MOCVD reactor cavity, many solid particles could be seen in the cavity. They are mainly covered on the base of the cavity, with an average thickness of about $2 \mathrm{~mm}$. The solid particles were tested by XRD and identified as ZnO solid particles, as shown in Fig. 1.

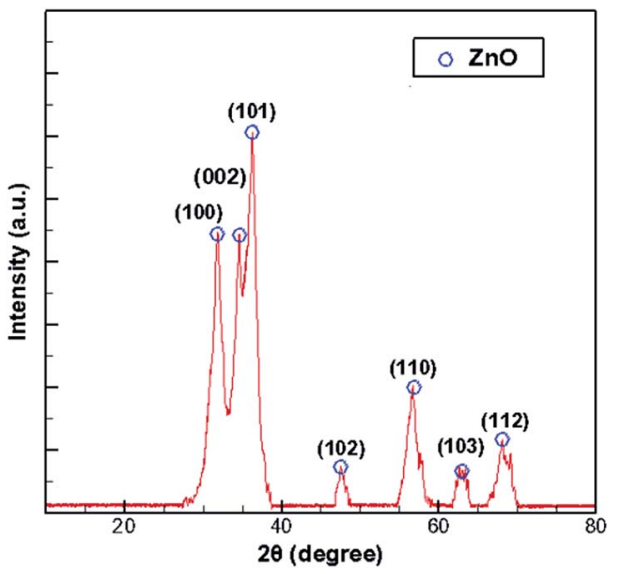

Fig. 1 Nanoparticles in the $\mathrm{ZnO}-\mathrm{MOCVD}$ reaction chamber and the $\mathrm{XRD}$ spectra of the $\mathrm{ZnO}$ particles.

The XRD pattern shows 7 peaks at $31.8^{\circ}, 34.4^{\circ}, 36.3^{\circ}$, $47.5^{\circ}, 56.6^{\circ}, 62.9^{\circ}, 68.0^{\circ}$, indexed to (100), (002), (101), (102), (110), (103), (112) planes of the ZnO crystal given by the standard data file (JCPDS card no. 36-1451). ${ }^{28}$ According to the Scherrer equation:

$$
D=\frac{K \lambda}{\beta \cos \theta},
$$

where $D$ is the grain diameter (nm), $K$ is a constant, $\lambda$ is X-ray wavelength, $\beta$ is the half peak width of diffraction angle, $\theta$ is the Prague diffraction angle. The average diameter of the particles with 7 peaks is $12.65 \mathrm{~nm}$. The nanoparticle definition designated by the National Nanotechnology Initiative has been adopted by the American National Standards Institute as particles with all dimensions between $1 \mathrm{~nm}$ and $100 \mathrm{~nm} .^{\mathbf{2 9 , 3 0}}$ Therefore, we believe that $\mathrm{ZnO}$ nanoparticles can be formed by a gas phase reaction. The study by $\mathrm{Chen}^{31}$ indicated that a trimer of zinc oxide $\left(\mathrm{Zn}_{3} \mathrm{O}_{3}\right)$ may be formed as a nanoparticle precursor. Oligomers form from the trimer and can nucleate to grow into nanoparticles. In the process of generating the trimer, the $\mathrm{Zn}$-containing gas component is adsorbed on the substrate surface to form a $\mathrm{ZnO}$ film.

The B3LYP/6-311G(d) ${ }^{32,33}$ level of theory as implemented in the GAUSSIAN 09 package $^{34}$ has been utilized in the full geometry optimizations of reactants, intermediates, products, and transition states (TS). Analytical vibrational frequency calculations have been performed for all optimized compounds on the same level of theory. Exactly, the stationary points (reactants, intermediates, and products) are characterized by zero imaginary vibrations while exactly one imaginary vibration characterizes transition structures. Each TS structure that connects two relevant stationary points is confirmed by the intrinsic reaction coordinate (IRC) ${ }^{35,36}$ calculations. For the structures of every point along each IRC calculation, singlepoint calculations in singlet state are performed to locate the spin conversion points where singlet and triplet potential energy surfaces (PES) crossing. The structures whose energies in triplet state nearly equal to that of the singlet state are the potential spin conversion points (CP), and they are the initial 


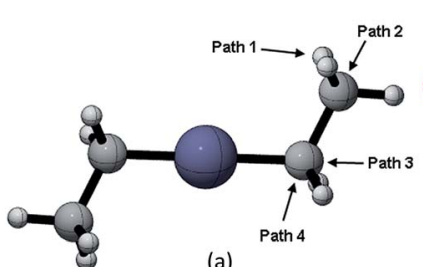

(a)

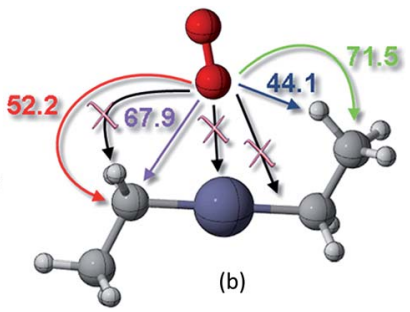

(b)
Fig. 2 (a) Different reaction paths for oxygen to attack on DEZn and their corresponding (b) energy barriers scenarios.

structures to input to geometry optimize on the same level using the modified version of Harvey's minimal energy crossing points (MECP) program, namely the sobMECP ${ }^{37,38}$ program. In order to obtain more accurate electronic energies during dehydration of zinc hydroxide, single-point calculations were performed at the $\operatorname{CCSD}(\mathrm{T}) / 6-311+\mathrm{G}(\mathrm{d}, \mathrm{p})$ level of theory for the B3LYP/6-311G(d)-optimized geometries. The optimized compounds are illustrated using CYLview $^{39}$ program to depict the electronic energy profile of the dominant reaction path.

\section{Gas phase reactions}

This study analyzed four different pathways for oxygen attack on DEZn: (1) $\mathrm{O}_{2}$ abstracts methyl $\mathrm{H}$, (2) $\mathrm{O}_{2}$ attacks on methyl C, (3) $\mathrm{O}_{2}$ attacks on methylene $\mathrm{C}$ to break $\mathrm{Zn}-\mathrm{C}$ bond, (4) $\mathrm{O}_{2}$ attacks on methylene $\mathrm{C}$ to break the $\mathrm{C}-\mathrm{C}$ bond, as shown in Fig. 2. The corresponding energy barriers for the attack scheme are determined according to the different attack pathways, as shown in Fig. 2(b). Kinetically, the main reaction path is methyl $\mathrm{H}$ abstraction.

The gas phase reaction paths and the energy barriers are shown in Fig. 3 and 4. (The spin conversion point is located in the path from IM2 to TS2. That is to say, during the process for the hydroxyl group of ${ }^{\circ} \mathrm{OOH}$ to attack the zinc atom and cleave the $\mathrm{Zn}-\mathrm{C}$ bond, the reaction is suggested to occur through a spin conversion point from triplet to singlet PES to generate IM4 on singlet PES instead of leading to TS2). Based on the formation process of $\mathrm{Zn}_{3} \mathrm{O}_{3}$, we identified nine gas phase reactions and calculated the kinetic parameters of the reaction kinetics of G1-G9, i.e., the prefactor and activation energy, using the parameter calculation method,,$^{17,18,40}$ as shown in Table 1. The reaction of DEZn and $\mathrm{O}_{2}$ is similar to that of DEZn and $\mathrm{H}_{2} \mathrm{O}$, and the reaction model of $\mathrm{ZnO}$ is similar to that in reference. ${ }^{23}$ That is, the process involves forming $\mathrm{Zn}(\mathrm{OH})_{2}$, then producing oligomers, and finally oligomer dehydration. In the model, we consider the complexation of triplet oxygen on the zinc site of DEZn (G1), methyl $\mathrm{H}$ abstraction by triplet oxygen (G2), spin conversion during the process for hydroxyl group of $\mathrm{HOO}^{*}$ to attack zinc atom (G3), intramolecular proton transfer of $\mathrm{HOOZnC}_{2} \mathrm{H}_{5}$ (G4), and hydroxyl group transfer of $\mathrm{HOCH}_{2}{ }^{-}$ $\mathrm{CH}_{2} \mathrm{ZnOH}$ leading to $\mathrm{Zn}(\mathrm{OH})_{2}$ (G5). The generation of $\mathrm{ZnO}$ by $\mathrm{Zn}(\mathrm{OH})_{2}$ alone requires an energy of $80.9 \mathrm{kcal} \mathrm{mol}^{-1}$, but the formation of oligomers makes $\mathrm{ZnO}$ more accessible (G6-G9), requiring only $39.2 \mathrm{kcal} \mathrm{mol}^{-1}$. With increasing temperature,

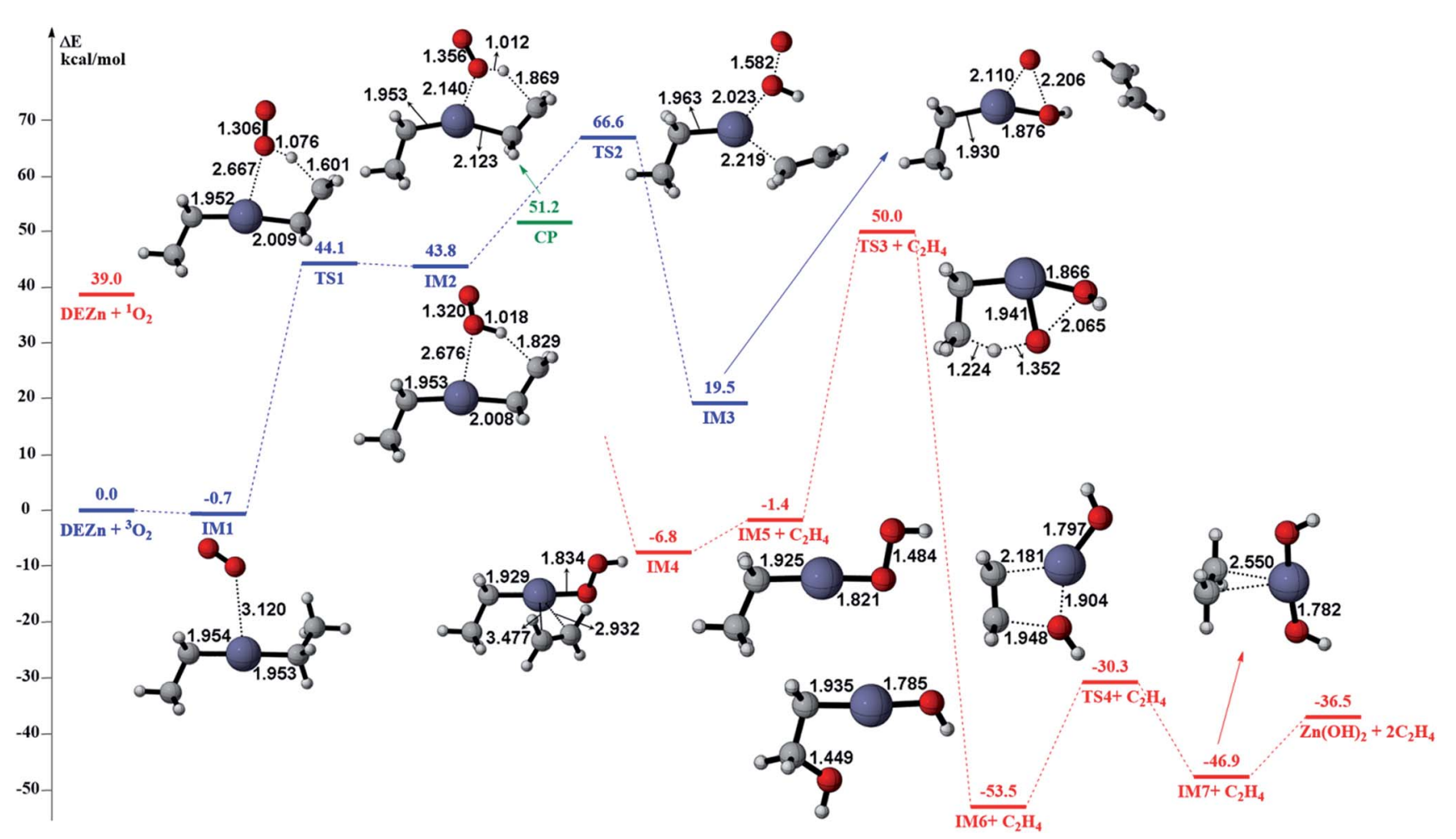

Fig. 3 The potential energy surface (PES) profile of the favourable reaction paths for the reaction $\mathrm{Zn}\left(\mathrm{C}_{2} \mathrm{H}_{5}\right)_{2}+3 \mathrm{O}_{2} \rightarrow \mathrm{Zn}(\mathrm{OH})_{2}+2 \mathrm{C}_{2} \mathrm{H}_{4}$. Energies are in $\mathrm{kcal} \mathrm{mol}^{-1}$ and distances are in angstrom. The reaction paths on triplet and singlet PES are illustrated in blue and red line respectively. The spin conversion point is illustrated in green line and denoted as CP. 


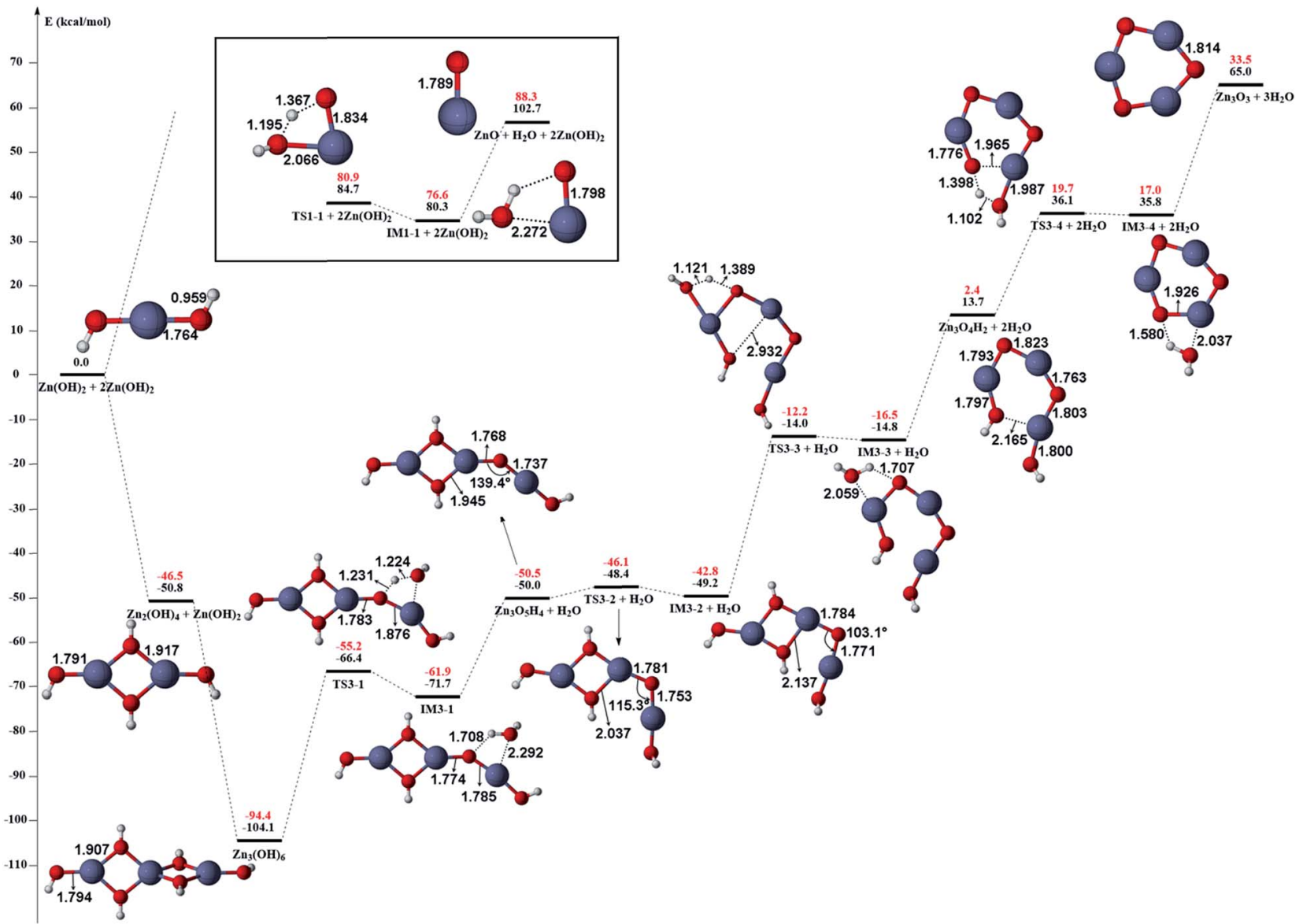

Fig. 4 The potential energy surface (PES) profile of zinc hydroxide dehydration computed at B3LYP/6-311G(d) (black) and CCSD(T)/6-311+G(d,p) (red) levels of theory. The relative electronic energies are given in $\mathrm{kcal} \mathrm{mol}^{-1}$ while the bond lengths are given in angstrom.

polymers aggregate into larger nanoparticles that are sent out with exhaust gas, resulting in lower utilization of gas. In the gas phase model, the chemical reaction paths in the ZnO-MOCVD reaction chamber is fully reflected by an addition reaction, adduct decomposition reaction, and polymerization reaction. At the same time, the simplicity of the model is maintained in order to reduce the computational cost.

The accuracy of the activation energies would make a great difference in CFD calculations. Thereby, the geometries optimized at the B3LYP/6-311G(d) level were used to carry out
$\operatorname{CCSD}(\mathrm{T})$ single-point energy calculations with $6-311+\mathrm{G}(\mathrm{d}, \mathrm{p})$ basis set. The electronic energy of the $\mathrm{CP}$ should be noted. Because the geometry of $\mathrm{CP}$ has been optimized at the B3LYP/6$311 \mathrm{G}(\mathrm{d})$ level, the electronic energy of singlet state for CP structure is nearly equal to the triplet one at the B3LYP/6$311 \mathrm{G}(\mathrm{d})$ level. However, there is a differential between the electronic energies from $\operatorname{CCSD}(\mathrm{T})$ single-point calculations of the CP singlet and triplet state. This could result in the difficulty in calculating the energy barriers of oxidation of DEZn at the $\operatorname{CCSD}(\mathrm{T}) / 6-311+\mathrm{G}(\mathrm{d}, \mathrm{p})$ level. Therefore, in Fig. 3, only the

Table 1 Gas phase reaction pathways and kinetic parameters from DEZn and $\mathrm{O}_{2}{ }^{a}$

\begin{tabular}{|c|c|c|c|c|}
\hline NO & Reactions & $A$ & $E_{\mathrm{a}}$ & $n$ \\
\hline G1 & $\mathrm{Zn}\left(\mathrm{CH}_{2} \mathrm{CH}_{3}\right)_{2}+\mathrm{O}_{2} \rightarrow \mathrm{Zn}\left(\mathrm{CH}_{2} \mathrm{CH}_{3}\right)_{2} \cdot \mathrm{O}_{2}$ & Coll & 0 & 0 \\
\hline G2 & $\mathrm{Zn}\left(\mathrm{CH}_{2} \mathrm{CH}_{3}\right)_{2} \cdot \mathrm{O}_{2} \rightarrow{ }^{\circ} \mathrm{CH}_{2} \mathrm{CH}_{2} \mathrm{ZnC}_{2} \mathrm{H}_{5} \cdot \mathrm{HOO} \cdot$ & $3.34 \times 10^{12}$ & 44.8 & 0 \\
\hline G4 & $\mathrm{HOOZnC}_{2} \mathrm{H}_{5} \rightarrow \mathrm{HOCH}_{2} \mathrm{CH}_{2} \mathrm{ZnOH}$ & $1.36 \times 10^{12}$ & 51.4 & 0 \\
\hline G5 & $\mathrm{HOCH}_{2} \mathrm{CH}_{2} \mathrm{ZnOH} \rightarrow \mathrm{Zn}(\mathrm{OH})_{2}+\mathrm{C}_{2} \mathrm{H}_{4}$ & $1.29 \times 10^{14}$ & 23.2 & 0 \\
\hline G6 & $3 \mathrm{Zn}(\mathrm{OH})_{2} \rightarrow \mathrm{Zn}_{3}(\mathrm{OH})_{6}$ & Coll & 0 & 0 \\
\hline G9 & $\mathrm{Zn}_{3} \mathrm{O}_{4} \mathrm{H}_{2} \rightarrow \mathrm{Zn}_{3} \mathrm{O}_{3}+\mathrm{H}_{2} \mathrm{O}$ & $1.08 \times 10^{12}$ & 17.3 & 0 \\
\hline
\end{tabular}

${ }^{a}$ Activation energies are in $\mathrm{kcal} \mathrm{mol}^{-1}$ and pre-exponentials are in $\mathrm{s}^{-1}$. 
Table 2 Surface reaction pathways and kinetic parameters for $\mathrm{ZnO}$ growth $^{a}$

\begin{tabular}{|c|c|c|c|}
\hline No. & Reaction & $A$ & $E_{\mathrm{a}}$ \\
\hline S1 & $\mathrm{Zn}\left(\mathrm{CH}_{2} \mathrm{CH} 3\right)_{2} \cdot \mathrm{O}_{2} \rightarrow \mathrm{ZnO}+2 \mathrm{C}_{2} \mathrm{H}_{4}+\mathrm{H}_{2} \mathrm{O}$ & $S=1$ & \\
\hline $\mathrm{S} 2$ & ${ }^{\circ} \mathrm{CH}_{2} \mathrm{CH}_{2} \mathrm{ZnC}_{2} \mathrm{H}_{5} \cdot \mathrm{HOO}^{\prime} \rightarrow \mathrm{ZnO}+2 \mathrm{C}_{2} \mathrm{H}_{4}+\mathrm{H}_{2} \mathrm{O}$ & $S=1$ & 0 \\
\hline S3 & $\mathrm{HOOZnC}_{2} \mathrm{H}_{5} \rightarrow \mathrm{ZnO}+2 \mathrm{C}_{2} \mathrm{H}_{4}+\mathrm{H}_{2} \mathrm{O}$ & $S=1$ & 0 \\
\hline S4 & $\mathrm{HOCH}_{2} \mathrm{CH}_{2} \mathrm{ZnOH} \rightarrow \mathrm{ZnO}+2 \mathrm{C}_{2} \mathrm{H}_{4}+\mathrm{H}_{2} \mathrm{O}$ & $S=1$ & 0 \\
\hline S5 & $\mathrm{Zn}(\mathrm{OH})_{2} \rightarrow \mathrm{ZnO}+\mathrm{H}_{2} \mathrm{O}$ & $S=1$ & 0 \\
\hline S6 & $\mathrm{Zn}_{3}(\mathrm{OH})_{6} \rightarrow 3 \mathrm{ZnO}+3 \mathrm{H}_{2} \mathrm{O}$ & $S=1$ & 0 \\
\hline S7 & $\mathrm{Zn}_{3} \mathrm{O}_{5} \mathrm{H}_{4} \rightarrow 3 \mathrm{ZnO}+2 \mathrm{H}_{2} \mathrm{O}$ & $S=1$ & 0 \\
\hline S8 & $\mathrm{Zn}_{3} \mathrm{O}_{4} \mathrm{H}_{2} \rightarrow 3 \mathrm{ZnO}+\mathrm{H}_{2} \mathrm{O}$ & $S=1$ & 0 \\
\hline
\end{tabular}

${ }^{a} S=1$ denotes a unity sticking coefficient at zero coverage. ${ }^{17,18}$ Activation energies are in $\mathrm{kcal} \mathrm{mol}^{-1}$.

barriers at the B3LYP/6-311G(d) level could be obtained and they are applied in the followed CFD calculation. For the dehydration of zinc hydroxide in gas phase, the reactions only occur on the singlet potential surface, so the $\operatorname{CCSD}(\mathrm{T}) / 6$ $311+\mathrm{G}(\mathrm{d}, \mathrm{p}) / / \mathrm{B} 3 \mathrm{LYP} / 6-311 \mathrm{G}(\mathrm{d})$ activation energies would be obtained (Fig. 4) and we use them in the CFD model. The relative energies in Fig. 4 reveal that the B3LYP/6-311G(d) energies overestimate the thermodynamical unfavorability. In other words, it could be inferred from the $\operatorname{CCSD}(\mathrm{T}) / 6-311+\mathrm{G}(\mathrm{d}, \mathrm{p})$ results that the $\mathrm{ZnO}$ solid particles in the cavity could be produced at lower temperature relative to the B3LYP/6-311G(d) results.

\section{Surface reactions}

In this study, a simplified surface reaction kinetic model is used to describe the surface growth of the film, as shown in Table 2. The principle and simplification of the model are as follows: (1) the growth rate does not depend on the number of $\mathrm{O}_{2}$ but depends only on the number of Zn-containing species that arrive at the substrate surface. (2) Considering that the energy barrier of the gas phase product generated after $\mathrm{Zn}\left(\mathrm{CH}_{2} \mathrm{CH}_{3}\right)_{2}$ - $\mathrm{O}_{2}$ is $44.8 \mathrm{kcal} \mathrm{mol}^{-1}$ (G2).

However, the adsorption reaction on the wall is lower in energy than the reaction temperature of the gas phase. Therefore, we use the activation energy of S1 as an adjustable parameter, ${ }^{21}$ which is determined by the $\mathrm{ZnO}$ growth rate and the literature value fitting method, and the adsorption energy of other surface reactions is 0 . (3) The surface adsorption and reactions of all gas containing species except $\mathrm{Zn}_{3} \mathrm{O}_{3}$ are considered in the model.

\section{CFD model and boundary conditions}

We used DEZn and $\mathrm{O}_{2}$ sources to model $\mathrm{ZnO}$ growth. The gases were injected from the showerhead to the chamber and were carried by Ar. A schematic diagram of the model is shown in Fig. 5(a), and the flow diagram is shown in Fig. 5(b). The MOCVD growth process of $\mathrm{ZnO}$ was performed in a low-pressure reactor with a laminar flow. The mixed gas can be treated as an ideal, incompressible gas mixture. The system was presumed to be in a steady state. The following assumptions and boundary

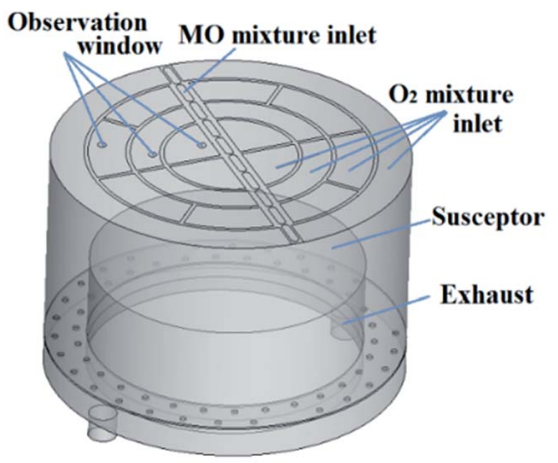

(a)

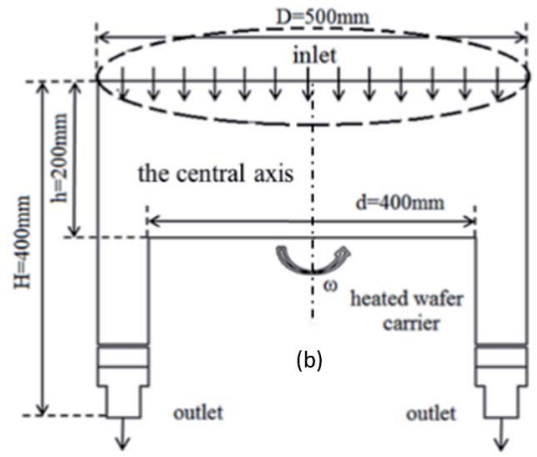

Fig. 5 (a) Simulation model diagram of $\mathrm{ZnO}-\mathrm{MOCVD}$ reaction chamber (b) two-dimensional flow diagram.

conditions were made in this study, under the premise that they have little effect on the main results:

(1) The MO and Ar carrier gas mixture enters the reactor through the central MO mixture inlet, and $\mathrm{O}_{2}$ mixture inlets are distributed on both sides in this model. Among them, the content of Ar is $15450 \mathrm{sccm}$, the DEZn content is $90 \mathrm{sccm}$, and the $\mathrm{O}_{2}$ content is $550 \mathrm{sccm}$.

(2) The graphite disc was assumed to have good thermal conductivity, and its temperature was assumed to be consistent with that of the substrate (423-1223 K). The rotation speed of the susceptor was set to $750 \mathrm{rpm}$, and the internal pressure of the cavity is 6.1 Torr.

(3) At the exhaust, the pressure-outlet boundary condition was applied, i.e., a static pressure of $0 \mathrm{~Pa}$ at the outlet.

\section{Verification and analysis of calculation results}

Fig. 6(a) shows normalization results from the literature ${ }^{\mathbf{4 1 , 4 2}}$ and CFD simulations of the growth rate of $\mathrm{ZnO}$ generated by the reaction of DEZn with $\mathrm{O}_{2}$ at different temperatures. It can be seen from the processed data that the numerical simulation of CFD is in good agreement consistent with the grow trend in Fig. 6(b), proving the feasibility of the current chemical reaction-transport model of DEZn with $\mathrm{O}_{2}$. Fig. 6 shows three distinct regimes: the growth rate of $\mathrm{ZnO}$ increases rapidly with the growth temperature below $673 \mathrm{~K}$ (regime I). The main reason for this increase is that the growth rate is affected by the 
(a)

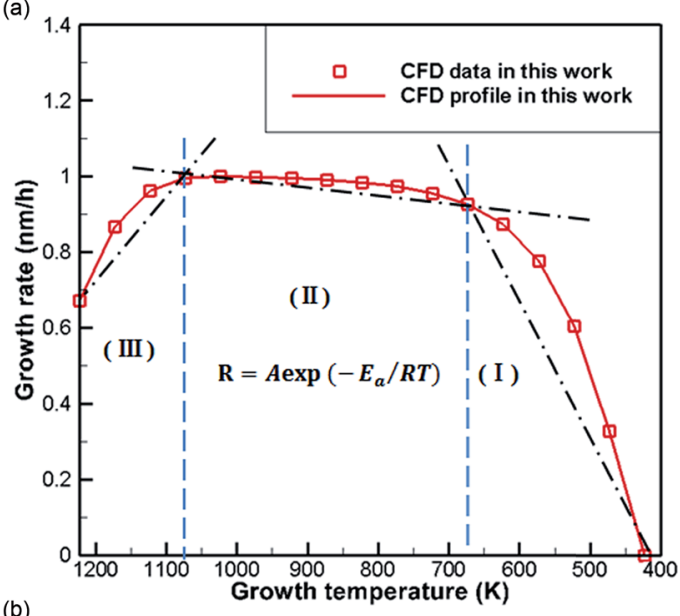

(b)

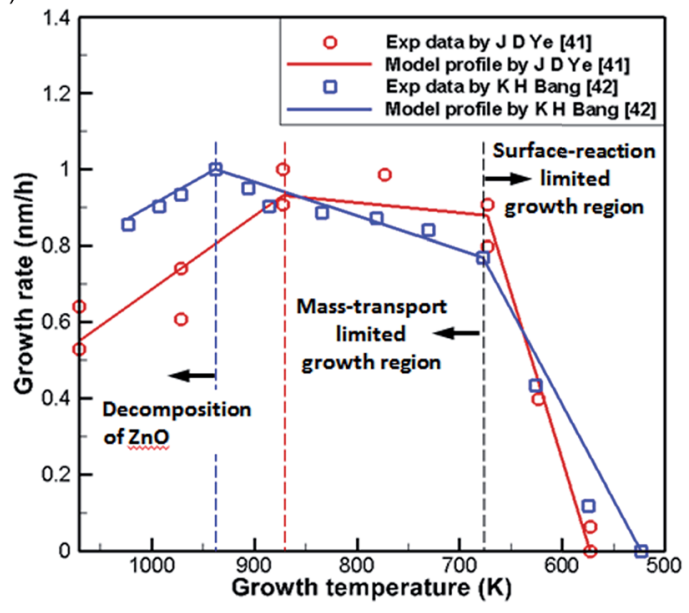

Fig. 6 (a) Normalization results of CFD simulations (b) Arrhenius plots of the growth rate versus reciprocal temperature in literature.

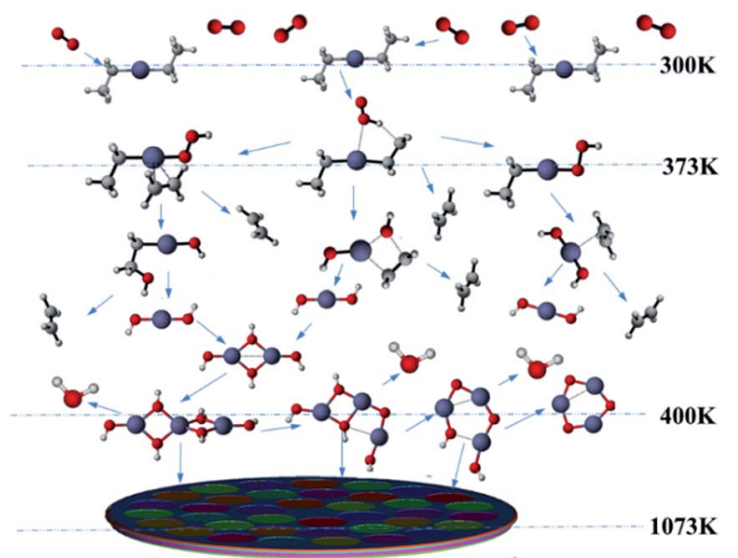

Fig. 8 Schematic illustration of the chemical reactions in the vapor phase in the MOCVD chamber.

surface reaction kinetics at a lower temperature. The lowtemperature region $(T<673 \mathrm{~K})$ and the numerical fitting of the literature are better, and the rationality of the $\mathrm{S} 1$ activation energy is proved. Above $1073 \mathrm{~K}$ (regime III), the rate of formation of nanoparticles exceeds the deposition rate of the films when the temperature is increased. Excessive $\mathrm{Zn}_{3} \mathrm{O}_{3}$ formation leads to a waste of resources, resulting in a decrease in the deposition rate of $\mathrm{ZnO}$. At 673-1073 K (regime II), the deposition rate changes relatively smoothly, and the growth rate is considered to be controlled by mass transport. In this interval, the growth efficiency is high, and the growth rate is less sensitive to the temperature.

To better reveal the chemical reaction state inside the cavity, we analyzed the $\mathrm{ZnO}$ deposition rate, which begins to decline at (a)

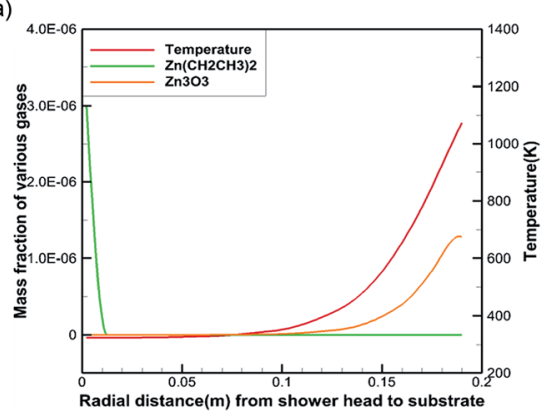

(c)

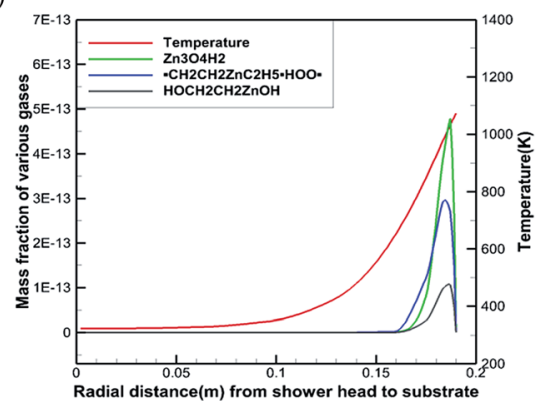

(b)

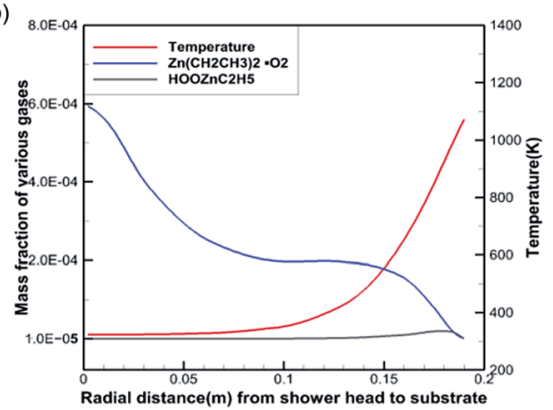

(d)

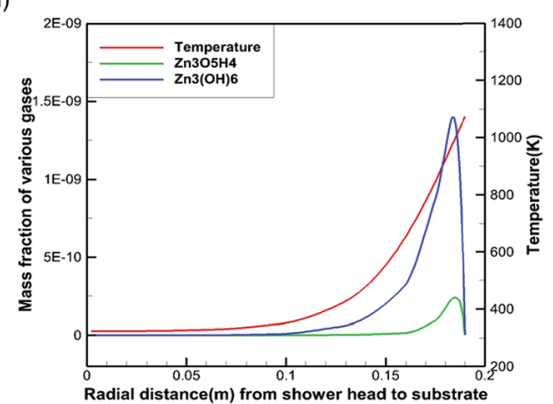

Fig. 7 Temperatures and mass fractions of the main component along the chamber radius. 
Table 3 Mass fraction of $\mathrm{Zn}_{3} \mathrm{O}_{3}$ at the substrate surface at different temperatures

\begin{tabular}{lllllllll}
\hline & \multicolumn{1}{l}{} & & & & \\
& $823 \mathrm{~K}$ & $873 \mathrm{~K}$ & $923 \mathrm{~K}$ & $973 \mathrm{~K}$ & $1023 \mathrm{~K}$ & $1073 \mathrm{~K}$ & $1123 \mathrm{~K}$ & $1173 \mathrm{~K}$ \\
\hline Mass fractions & $8.78 \times 10^{-13}$ & $5.60 \times 10^{-11}$ & $1.62 \times 10^{-9}$ & $2.62 \times 10^{-8}$ & $2.63 \times 10^{-7}$ & $1.27 \times 10^{-6}$ & $6.59 \times 10^{-6}$ & $1.98 \times 10^{-5}$
\end{tabular}

1073 K. Fig. 7 depicts the mass fraction of different $\mathrm{Zn}$ sources in the gas mixture on the central axis of the cavity at $1073 \mathrm{~K}$. It can be concluded that the mass fraction contour can provide a basis to better understand the mass transfer and reaction mechanisms in the reactor. At $300 \mathrm{~K}$, DEZn and $\mathrm{O}_{2}$ react violently with each other to form $\mathrm{Zn}\left(\mathrm{CH}_{2} \mathrm{CH}_{3}\right)_{2} \cdot \mathrm{O}_{2}$ after the formation of mixed complexes, as shown in Fig. 7(a) and (b). In the cavity, $\mathrm{Zn}\left(\mathrm{CH}_{2} \mathrm{CH}_{3}\right)_{2} \cdot \mathrm{O}_{2}$ is the most abundant species. In the cavity, $\mathrm{Zn}\left(\mathrm{CH}_{2} \mathrm{CH}_{3}\right)_{2} \cdot \mathrm{O}_{2}$ is the most abundant species, which decomposes in the reaction chamber, thus, reaction $\mathrm{G} 2$ is the decisive step of the whole reaction. At even higher temperatures, $\mathrm{Zn}\left(\mathrm{CH}_{2} \mathrm{CH}_{3}\right)_{2} \cdot \mathrm{O}_{2}$ continually decomposes. At $373 \mathrm{~K}$, $\mathrm{HOOZnC}_{2} \mathrm{H}_{5}$ begins to be generated. At $400 \mathrm{~K}$, the simultaneous occurrence of $\mathrm{Zn}_{3}(\mathrm{OH})_{6}$ and $\mathrm{Zn}_{3} \mathrm{O}_{3}$ prove that both $\mathrm{Zn}_{3} \mathrm{O}_{5} \mathrm{H}_{4}$ and $\mathrm{Zn}_{3} \mathrm{O}_{4} \mathrm{H}_{2}$ have been completely reacted at this point, as shown in Fig. 7(c) and (d). However, at higher temperatures, more $\mathrm{Zn}_{3} \mathrm{O}_{3}$ is formed on the substrate surface, which affects the deposition rate and film quality.

Based on our results, the reaction path of DEZn oxidization in this MOCVD reaction chamber is shown at $1073 \mathrm{~K}$ in Fig. 8. When the temperature is greater than $400 \mathrm{~K}, \mathrm{Zn}_{3} \mathrm{O}_{3}$ is produced within the cavity, leading to nanoparticle formation. This process can occur alongside the growth of the film.

The difference between the present results and previous studies is that the decomposition reaction does not just occur in regime III. Only $\mathrm{Zn}_{3} \mathrm{O}_{3}$ is generated in large amounts in this temperature region, resulting in a decrease in the deposition rate of $\mathrm{ZnO}$. Thus, we observed the content of $\mathrm{Zn}_{3} \mathrm{O}_{3}$ at 823-1173 K to better determine the growth range, as shown in Table 3. Little $\mathrm{Zn}_{3} \mathrm{O}_{3}$ (mass fractions below $1 \times 10^{-10}$ ) was produced below 873 K. For this reason, we believe that the optimum growth temperature range of $\mathrm{ZnO}$ from DEZn and $\mathrm{O}_{2}$ is $673-873 \mathrm{~K}$.

\section{Conclusion}

We proposed a chemical reaction-transport model for $\mathrm{ZnO}$ production by the reaction of DEZn with $\mathrm{O}_{2}$ during MOCVD. The kinetic parameters of the reaction steps were obtained using quantum chemistry calculations. Based on these data, the reaction and $\mathrm{ZnO}$ deposition processes in a MOCVD system were studied using CFD software. The following conclusions can be drawn.

(1) The nanoparticles formed inside the ZnO-MOCVD cavity were analyzed by XRD, and the main component of the nanoparticles was $\mathrm{ZnO}$. Therefore, it is speculated that there is a corresponding path of $\mathrm{ZnO}$ formation from oligomers during the gas phase reaction.

(2) According to the different routes of oxygen attack on DEZn, the chemical reaction path is determined by the minimum energy principle, that is, the main reaction path is $\mathrm{O}_{2}$ capture by methyl $\mathrm{H}$. $\mathrm{Zn}_{3} \mathrm{O}_{3}$ was identified as the initiator for nanoparticles to form oligomers that then nucleated into $\mathrm{ZnO}$. Finally, the gas phase reaction was determined to involve the following conversion pathway: DEZn to $\mathrm{Zn}(\mathrm{OH})_{2}$ to $\mathrm{Zn}_{3} \mathrm{O}_{3}$.

(3) The high temperature required by gas phase reaction means that the gas phase component containing $\mathrm{Zn}$ in the G1 path is adsorbed on the surface of the substrate during the lowtemperature process, leading predominantly to film formation. The activation energy of $\mathrm{S} 1$ chemical reaction is estimated, and the activation energy of the equation is $9.56 \mathrm{kcal} \mathrm{mol}^{-1}$, the tendency of deposition rate of substrate film calculated by CFD is consistent with the experimental in the literature.

(4) The chemical kinetic parameters were integrated into the CFD analysis to validate the experimental observations in a MOCVD chamber. The effect of the temperature distribution on the $\mathrm{ZnO}$ film growth rate was discussed. At low temperatures $(<673 \mathrm{~K})$, the growth rate of the films is exponential and controlled by the surface reaction kinetics. In the region of 673$1073 \mathrm{~K}$, the film growth rate is stable and mainly controlled by the gas flow rate. When the temperature is higher than $1073 \mathrm{~K}$, the growth rate of the thin films is reduced, possibly due to the formation of nanoparticles from the gas phase polymer.

(5) The analysis of the $\mathrm{Zn}_{3} \mathrm{O}_{3}$ nanoparticles precursor at different temperatures shows that the amount of $\mathrm{Zn}_{3} \mathrm{O}_{3}$ produced below $873 \mathrm{~K}$ is very low, the mass fraction of $\mathrm{Zn}_{3} \mathrm{O}_{3}$ is $1 \times 10^{-5}$ of $\mathrm{Zn}\left(\mathrm{CH}_{2} \mathrm{CH}_{3}\right)_{2} \cdot \mathrm{O}_{2}$ and $1 \times 10^{-2}$ of $\mathrm{HOOZnC}_{2} \mathrm{H}_{5}$. Therefore, to prevent pre-reaction, the optimum DEZn and $\mathrm{O}_{2}$ reactions yield $\mathrm{ZnO}$ film material with a temperature of 673-873 K.

\section{Experimental}

XRD spectra were recorded using a D8 Advance X-ray diffractometer (Bruker, Germany). The high precision goniometer guaranteed that the errors in the peak position and standard peak position of each diffraction peak in the full spectrum range was not more than 0.01 degrees

\section{Conflicts of interest}

There are no conflicts to declare.

\section{Acknowledgements}

We would like to thank the National Natural Science Foundation of China (21273081, 21673085) and Natural Funds of Guangdong Province (grant no. 2015A030311050) for providing the finance support for this project. We also appreciate the 
support of the National Supercomputing Center (NSCC) in Guangzhou and the Linux PC clusters at SCNU for computing resources.

\section{Notes and references}

1 B. J. Jin, S. H. Bae, S. Y. Lee and S. Im, Mater. Sci. Eng., B, 2000, 71, 301-305.

2 Y. J. Chen, Y. Y. Shih, C. H. Ho, J. H. Du and Y. P. Fu, Ceram. Int., 2010, 36, 69-73.

3 J. Lim, K. Shin, H. Woo Kim and C. Lee, J. Lumin., 2004, 109, 181-185.

4 R. F. Service, Science, 1997, 276, 895.

5 A. Tsukazaki, A. Ohtomo, T. Onuma, M. Ohtani, T. Makino, M. Sumiya, K. Ohtani, S. F. Chichibu, S. Fuke and Y. Segawa, Nat. Mater., 2010, 4, 42-46.

6 X. Li, B. Zhang, X. Dong, Y. Zhang, X. Xia, W. Zhao and G. Du, J. Lumin., 2009, 129, 86-89.

7 C. H. Chen, H. Liu, D. Steigerwald, W. Imler, C. P. Kuo, M. G. Craford, M. Ludowise, S. Lester and J. Amano, J. Electron. Mater., 1996, 25, 1004-1008.

8 S. Mazumder and S. A. Lowry, J. Cryst. Growth, 2001, 224, 165-174.

9 J. R. Creighton, G. T. Wang, W. G. Breiland and M. E. Coltrin, J. Cryst. Growth, 2004, 261, 204-213.

10 D. Sengupta, S. Mazumder, W. Kuykendall and S. A. Lowry, J. Cryst. Growth, 2005, 279, 369-382.

11 A. Hirako and K. Ohkawa, J. Cryst. Growth, 2006, 289, 428-432. 12 I. T. Im, H. J. Oh, M. Sugiyama, Y. Nakano and Y. Shimogaki, J. Cryst. Growth, 2004, 261, 214-224.

13 I. T. Im, M. Sugiyama, Y. Shimogaki and Y. Nakano, J. Cryst. Growth, 2005, 276, 431-438.

14 H. Song, M. Sugiyama, Y. Nakano and Y. Shimogaki, J. Electrochem. Soc., 2007, 154, H91-H96.

15 M. Sugiyama, K. Kusunoki, Y. Shimogaki, S. Sudo, Y. Nakano, H. Nagamoto, K. Sugawara, K. Tada and H. Komiyama, Appl. Surf. Sci., 1997, 117, 746-752.

16 K. Harafuji, Y. Hasegawa, A. Ishibashi, A. Tsujimura, I. Kidoguchi, Y. Ban and K. Ohnaka, Jpn. J. Appl. Phys., Part 1, 2000, 39, 6180-6190.

17 C. Theodoropoulos, T. J. Mountziaris, H. K. Moffat and J. Han, J. Cryst. Growth, 2000, 217, 65-81.

18 R. P. Parikh and R. A. Adomaitis, J. Cryst. Growth, 2006, 286, 259-278.

19 A. V. Lobanova, E. V. Yakovlev, R. A. Talalaev, S. B. Thapa and F. Scholz, J. Cryst. Growth, 2008, 310, 4935-4938.

20 T. G. Mihopoulos, V. Gupta and K. F. Jensen, J. Cryst. Growth, 1998, 195, 733-739.

21 C. Theodoropoulos, N. K. Ingle, T. J. Montziaris, Z. Y. Chen, P. L. Liu, G. Kioseoglou and A. Petrou, J. Electrochem. Soc., 1995, 142, 2086-2093.

22 H. Dumont, A. Marbeuf, J. E. Bourée and O. Gorochov, Mater. Sci. Eng., B, 1993, 17, 41-46.

23 S. M. Smith and H. B. Schlegel, Chem. Mater., 2003, 15, 162166.
24 B. H. Munk and H. B. Schlegel, Chem. Mater., 2006, 18, 18781884.

25 Y. S. Kim and Y. S. Won, Bull. Korean Chem. Soc., 2009, 30, 1573-1578.

26 A. Afshar and K. C. Cadien, Appl. Phys. Lett., 2013, 103, 251906.

27 K. Maejima and S. Fujita, J. Cryst. Growth, 2006, 293, 305310.

28 JCPDS Card No. 36-451, Crytalstar, Swarthmore, PA, USA.

29 FAQs, Nanotechnology, National Nanotechnology Initiative, 2010.

30 G. Lövestam, H. Rauscher, G. Roebben, B. S. Klüttgen, N. Gibson, J. P. Putaud and H. Stamm, in JCR Reference Reports, ed. J. R. Centre, Luxembourg, 2010, p. 40.

31 M. Chen, T. P. Straatsma, Z. Fang and D. A. Dixon, J. Phys. Chem. C, 2016, 120, 20400-20418.

32 A. D. Becke, J. Chem. Phys., 1993, 98, 5648-5652.

33 C. Lee, W. Yang and R. G. Parr, Phys. Rev. B: Condens. Matter Mater. Phys., 1988, 37, 785.

34 M. J. Frisch, G. W. Trucks, H. B. Schlegel, G. E. Scuseria, M. A. Robb, J. R. Cheeseman, G. Scalmani, V. Barone, B. Mennucci, G. A. Petersson, H. Nakatsuji, M. Caricato, X. Li, H. P. Hratchian, A. F. Izmaylov, J. Bloino, G. Zheng, J. L. Sonnenberg, M. Hada, M. Ehara, K. Toyota, R. Fukuda, J. Hasegawa, M. Ishida, T. Nakajima, Y. Honda, O. Kitao, H. Nakai, T. Vreven, J. A. Montgomery, J. E. Peralta, F. Ogliaro, M. Bearpark, J. J. Heyd, E. Brothers, K. N. Kudin, V. N. Staroverov, T. Keith, R. Kobayashi, J. Normand, K. Raghavachari, A. Rendell, J. C. Burant, S. S. Iyengar, J. Tomasi, M. Cossi, N. Rega, J. M. Millam, M. Klene, J. E. Knox, J. B. Cross, V. Bakken, C. Adamo, J. Jaramillo, R. Gomperts, R. E. Stratmann, O. Yazyev, A. J. Austin, R. Cammi, C. Pomelli, J. W. Ochterski, R. L. Martin, K. Morokuma, V. G. Zakrzewski, G. A. Voth, P. Salvador, J. J. Dannenberg, S. Dapprich, A. D. Daniels, O. Farkas, J. B. Foresman, J. V. Ortiz, J. Cioslowski and D. J. Fox, Gaussian 09, revision D.01, Gaussian Inc., Wallingford, CT, 2013.

35 K. Fukui, J. Phys. Chem., 1970, 74, 4161-4163.

36 K. Fukui, Acc. Chem. Res., 1981, 14, 471-476.

37 J. N. Harvey, M. Aschi, H. Schwarz and W. Koch, Theor. Chem. Acc., 1998, 99, 95-99.

38 J. N. Harvey and M. Aschi, Phys. Chem. Chem. Phys., 1999, 1, 5555-5563.

39 C. Y. Legault, CYLView, version $1.0 \mathrm{~b}$, Université de Sherbrooke, Sherbrooke, Quebec, Canada, 2009.

40 M. G. Evans and M. Polanyi, Trans. Faraday Soc., 1935, 31, 875.

41 J. D. Ye, S. L. Gu, S. M. Liu, S. M. Zhu, R. Zhang, Y. Shi, Y. D. Zheng, X. W. Sun, G. Q. Lo and D. L. Kwong, Appl. Phys. Lett., 2007, 90, 241108.

42 K. H. Bang, D. K. Hwang, S. W. Lim and J. M. Myoung, J. Cryst. Growth, 2003, 250, 437-443. 